Research Article

\title{
A Low-Cost and Low-Density Cement Slurry System Suitable for a Shallow Unconsolidated Stratum
}

\author{
Jiaping Yue, ${ }^{1,2}$ Zhaonian Liu, ${ }^{1,2}$ Jie Wang $\mathbb{D}^{3}{ }^{3}$ Ting Sun $\mathbb{D}^{3}{ }^{3}$ Zhiqiang Wu, \\ and Yanan Geng ${ }^{1,2}$ \\ ${ }^{1}$ State Key Laboratory of Offshore Oil Exploitation, Beijing 100028, China \\ ${ }^{2}$ CNOOC Research Institute Co., Ltd., Beijing 100028, China \\ ${ }^{3}$ China University of Petroleum, Beijing 102249, China
}

Correspondence should be addressed to Jie Wang; 1621373771@qq.com

Received 27 December 2019; Revised 23 April 2020; Accepted 12 May 2020; Published 11 June 2020

Academic Editor: Dimitrios E. Manolakos

Copyright (c) 2020 Jiaping Yue et al. This is an open access article distributed under the Creative Commons Attribution License, which permits unrestricted use, distribution, and reproduction in any medium, provided the original work is properly cited.

The shallow unconsolidated stratum in the offshore oilfield is characterized by large porosity, low temperature, and weak formation and often faces problems such as low density and poor compressive strength of a cement slurry, among others, which pose serious challenges to construction. A high-performance low-density cement slurry system must be used for cementing to ensure the safety of subsequent drilling and mining on-site and to reduce the cost of cement slurry for the efficient development of oil and gas fields. Based on these problems, according to the principle of particle gradation, a mixture with a high accumulation rate and low density composed of five types of mineral materials, i.e., artificial microbeads, floating beads, microsilicon, fly ash, and slag, has been developed through a large number of indoor experiments, and a set of low-cost and low-density cement slurry systems has been developed; these systems are suitable for the shallow loose formations of offshore oil fields. The cement slurry system meets the requirements of the cementing operation conducted under different temperatures and pressures. The density range is $1.4-1.7 \mathrm{~g} / \mathrm{cm}^{3}$, which can be adjusted. The cement slurry is stable and exhibits good fluidity. The thickening time meets the requirements of cementing construction. Moreover, the compressive strength of the cement paste is high, and the compressive strength of cement paste is greater than $12 \mathrm{MPa}$ for $24 \mathrm{~h}$ and $14 \mathrm{MPa}$ for $48 \mathrm{~h}$ of curing at $50^{\circ} \mathrm{C}$, which maximizes the economic benefits. The research results provide technical support for the safe and efficient development of offshore oil and gas fields.

\section{Introduction}

The cement slurry system has a low compressive strength, slow development, and poor cementation quality at the second interface and other problems caused by the high porosity, poor cementation degree, and low temperature of the unconsolidated sandstone stratum in the offshore oilfield [1]. High-performance, high-quality lightening admixtures (such as glass beads) and additives are always used to improve the well cementing quality and ensure the safe construction of the oil field, which also results in a substantial increase in the cost of well cementing; additionally, due to low oil prices, methods that reduce the cost of well cementing are urgently needed.
Three relatively mature technologies exist for the preparation of a low-density cement slurry:

(1) Increasing the liquid-to-solid ratio by adding viscous, solid inorganic substances, organic high-waterabsorbent materials, and lightweight fillers, such as bentonite, diatomaceous earth, and expanded perlite

(2) Adding glass beads and other similar materials to replace some of the cement based on the lower density of the material itself to reduce the density, such as fly ash, floating beads, glass beads, ceramic beads, and other materials [2]

(3) Using foam cement in which a gas, typically nitrogen, is mechanically or chemically charged into the 
cement to reduce the density of the cement slurry system [3]

The density of the general low-density system has a minimum limit. For example, the minimum densities of bentonite, diatomaceous earth, fly ash, and floating bead cement slurries are $1.60 \mathrm{~g} / \mathrm{cm}^{3}, 1.50 \mathrm{~g} / \mathrm{cm}^{3}, 1.55 \mathrm{~g} / \mathrm{cm}^{3}$, and $1.38 \mathrm{~g} / \mathrm{cm}^{3}$, respectively; if these values are reduced, the cement slurry displays poor performance, particularly the compressive strength $[4,5]$. Currently, the use of microbeads as a lightening admixture in China's offshore oilfields meets the well cementing requirements, but the cost is too high. Using fly ash, bentonite, and slag as lightening admixtures, the cost will be greatly reduced, but the cement slurry will exhibit poor stability, low compressive strength, and other shortcomings and might not even meet the well cementing requirements.

From the perspective of material science, the low-density cement slurry system is a mixture of oil well cement, admixture, and additive. From the perspective of oil and gas well engineering, the system must be able to withstand the test of complex downhole working conditions, and the performance of the system, such as the density, rheological property, and stability, must meet the needs of the cementing operation and subsequent links. The admixture of mineral material, system compactness, and additive are the main factors affecting the performance of the low-density cement slurry system $[6,7]$. The three factors influence each other and are inseparable. Mineral materials exert substantial effects on the density, rheological property, and strength of a cement slurry system [8]. An increase in the compactness of cement slurry system is conducive to improving the solid phase content per unit volume of the system, thus increasing the strength $[9,10]$. The additive is mainly used to maintain the stability of cement slurry system, control water loss, and adjust the thickening time $[11,12]$. Therefore, the three main factors that affect the performance of cement, namely, the mineral material, densities of accumulation, and additive, must be grasped and a high-performance low-density cement slurry system must be constructed through systematic research to solve the problems associated with the scientific design and application of a low-density cement slurry.

Therefore, the authors developed a new low-density mixed material suitable for an offshore shallow unconsolidated stratum through a compound study of traditional lightening admixtures, active materials, and high-performance materials based on the principle of the particle size distribution. The low-density mixed material used as a lightening admixture, complemented with other admixtures, forms a low-density $\left(1.40 \mathrm{~g} / \mathrm{cm}^{3}-1.70 \mathrm{~g} / \mathrm{cm}^{3}\right)$ cement slurry that features a low-cost and excellent performance. According to the experimental results, the low-density cement slurry system forms a stable slurry with good fluidity, an adjustable thickening time, less fluid loss, $24 \mathrm{~h}$ compressive strength greater than $12 \mathrm{MPa}$, and $48 \mathrm{~h}$ compressive strength greater than $14 \mathrm{MPa}$ and meets the demand of well cementing for shallow unconsolidated sandstone in the offshore oilfield.

\section{Materials and Methods}

2.1. Experimental Materials. The cementing materials obtained from SanXia Cement Co., Ltd., China, were conventional class $\mathrm{G}$ oil well cement. A retarder, a dispersant, and a defoamer were purchased from Jingzhou Jiahua Technology Co., Ltd., China. The function of the retarder is to adjust the thickening time of the cement slurry, the dispersant improves the fluidity of the cement slurry, and the defoamer is used to reduce the number of bubbles in the cement slurry. An early strength agent and a filtration reducer were produced in the laboratory. The early strength agent improves the early strength of the cement slurry, and a filtration reducer is mainly used to decrease the water lost from the cement slurry.

The microbead is an artificially fabricated silicate glass sphere with a high compressive strength that is not easily broken [13]. It has several damage grades, the most common of which are $2000 \mathrm{psi}, 4000 \mathrm{psi}, 6000 \mathrm{psi}$, and 10,000 psi. A higher grade indicates better performance and a more expensive material; some high grades are not commonly used in well cementing [14].

The floating bead is also called the volcanic ash microbead, which is a byproduct of coal combustion and is a hollow volcanic ash sphere, and its compressive strength is approximately 3000 psi [15].

Microsilicon is composed of amorphous silica spheres with an average particle diameter ranging from $0.1 \mu \mathrm{m}$ to $1.0 \mu \mathrm{m}$ and a purity of approximately $90 \%$, and it is useful for improving the strength of cement stone [16].

The chemical composition of fly ash is mainly $\mathrm{SiO}_{2}$ and $\mathrm{Al}_{2} \mathrm{O}_{3}$, but it also contains small amounts of $\mathrm{Fe}_{2} \mathrm{O}_{3}, \mathrm{CaO}$, $\mathrm{Na}_{2} \mathrm{O}, \mathrm{K}_{2} \mathrm{O}$, and $\mathrm{SiO}_{3}$. Table 1 lists the main components of the slag [17].

\subsection{Experimental Methods}

2.2.1. Procedure Used to Prepare the Slurry. The cement slurry was prepared in accordance with the relevant provisions of the national standard GB/T 10238-2005. The cement slurry was prepared with a constant speed agitator (tg-3060a, Shenyang Taige Petroleum Instrument Co., Ltd.). Due to the presence of microbeads, the floating beads are damaged under high-speed stirring, and the speed of agitator should be maintained at less than $4000 \mathrm{r} / \mathrm{min}$.

2.2.2. Density. Because microbeads, floating beads, and other lightening materials are present in the dry mix, these materials will be damaged at a certain pressure, and thus, a liquid density meter (xym-3, Qingdao ChuangMeng Instrument Technology Service Co., Ltd.) must be used to determine the density of the cement slurry before and after breakage.

2.2.3. Slurry Rheology. The rheological test uses a rotational viscometer (OFITE900, OFITE, USA) to test the apparent flow characteristics of the cement slurry. The readings at different speeds from $3 \mathrm{rpm}$ to $300 \mathrm{rpm}$ were acquired to 
TABLE 1: Main components of the slag.

\begin{tabular}{lcccc}
\hline $\mathrm{CaO}$ & $\mathrm{Al}_{2} \mathrm{O}_{3}$ & $\mathrm{MgO}$ & $\mathrm{SiO}_{2}$ & $\mathrm{Fe}_{2} \mathrm{O}_{3}$ \\
\hline $30-50 \%$ & $7 \%-12 \%$ & $1 \%-15 \%$ & $25 \%-41 \%$ & $0.2 \%-5.1 \%$ \\
\hline
\end{tabular}

calculate the plastic viscosity, shear force, and other parameters of the slurry.

2.2.4. Thickening Time. This test determines the thickening time of the cement slurry under downhole conditions, and the thickening time is related to the time at which the cement slurry remains liquid and is pumped efficiently. The thickening time of the slurry was measured with a pressurized consistometer (TG-8040DA, Shenyang Taige Oil Equipment Co., Ltd., China).

2.2.5. Fluid Loss. The slurry fluid loss was measured with a HPHT filter press (TG-71, Shenyang Taige Oil Equipment Co., Ltd., China). The fluid loss was tested by measuring the volume of the filtrate passing through a standard sieve for 30 minutes under a pressure difference of $6.9 \mathrm{MPa}$.

2.2.6. Free Water and Slurry Sedimentation Tests. Water will separate from the slurry and concentrate on the top of the slurry for a period of time before the cement slurry solidifies and is called the free water. It is measured using a graduated cylinder with a volume of $250 \mathrm{~mL}$ to measure the volume of the free water on the top surface of the cement after 2 hours. The sedimentation test helps determine whether the solidphase particles settle out of the slurry and is used in conjunction with the free water test to determine the stability of the cement slurry under downhole conditions. Its aim is to determine the density of different positions at the top, middle, and bottom of the slurry after the slurry has been cured for 24 hours.

2.2.7. Compressive Strength. The compressive strength test indicates the strength of the cement slurry after it is pumped into the well and allowed to solidify. It determines the integrity of the cement and its ability to withstand long-term stress. In this experiment, the cement slurry was poured into a $50.8 \mathrm{~mm}$ mold and cured for $24 \mathrm{~h}$ at $50^{\circ} \mathrm{C}$ at $2 \mathrm{MPa}$. At the end of the curing process, the mold was removed, the sample was crushed with a universal testing machine (HY-20080, Shanghai Hengyi Precision Instrument Co., Ltd., China), and the maximum strength before crushing was recorded.

\section{Results and Discussion}

3.1. Optimal Design of Low-Density Concrete. The key to reducing the cost of low-density cement slurry systems is to minimize the use of high-cost materials such as microbeads and to meet the performance requirements of cement slurry in other ways; active materials and ultrafine gel materials are able to meet these requirements. Microsilicon with a small particle size is a good plugging agent that effectively fills the voids in the cement particles and increases the PVF value of the cement slurry; in addition, the microsilicon hydration reaction produces a C-S-H gel and increases the strength of the cement stone. Both fly ash and slag exert a pozzolanic effect, promote the hydration reaction, produce more $\mathrm{C}-\mathrm{S}-\mathrm{H}$ gel in the cement slurry, and increase the strength of cement stone. Additionally, fly ash is the product of coal combustion and slag is the product of blast furnace iron burning, both of which are very cheap and available.

To satisfy the well cementing requirements of the shallow unconsolidated sandstone stratum and effectively reduce the cost, the authors of this paper developed a five-element compounded low-density mixture based on microbeads, floating beads, microsilicon, slag, and fly ash. The experimental pressure used in the present study was approximately $25 \mathrm{MPa}$, and thus microbeads at the grade of 4000 psi were selected.

The floating beads were first with the microbeads to reduce the cost and form a cement slurry with excellent performance. According to the experimental results (see Table 2), as the quantity of power-plant floating beads increases, the rheology reading of the cement slurry becomes larger, the slurry becomes increasingly thicker, and the compressive strength continuously decreases. When the ratio of floating beads to microbeads is greater than $3: 7$, the compressive strength of cement stone decreases obviously; the power-plant floating beads were mixed with artificial floating beads at a ratio of $3: 7$ to form a mixed microbead material, reduce the cost of the cement slurry, and maintain its performance. The matching of the low-density mixture was finally determined, as shown in Table 3.

This study also tested the particle size distribution of the low-density mixture, as shown in Figure 1. The particle size distribution of different single materials differs, as shown in Figures 1(a)-1(d). The particle size of the material ranges from small to large as microsilicon, slag, fly ash, and microbeads. After materials are mixed into the low-density mixture, the particle size distribution of the material has a wider range, in which solid-phase particles are distributed from $1 \mu \mathrm{m}$ to $150 \mu \mathrm{m}$, and the particle size distribution is more even than a single material, thus contributing to the formation of a particle size distribution structure within cement and improving the performance of the cement slurry. As shown in Figure 2, the mixture of particles is distributed in the cement stone, no obvious voids are present, and the structure is relatively compact, which effectively improve the strength of the cement stone.

Professor Huang proposed the principle of the particle size distribution and established a close-packing model [18]. He suggested that the model should be used as the basis for optimizing the cement slurry system. The main parameter for measuring the degree of close packing is the packing volume fraction (PVF), which is defined as the spatial volume (absolute volume) occupied by solid particles in the dry mix divided by the total volume of solid particles plus the void space (volume) between them. The PVF resulting from the random distribution of spheres at the same particle size is approximately 0.64 , while the PVF obtained from the PSD generally exceeds 0.80 [19]. The larger the PVF value, the higher the degree of close packing and the better the 
TABLE 2: Effect of the ratio of mixing floating beads on the cement slurry.

\begin{tabular}{lccccccc}
\hline Floating beads: microbeads & Density $\left(\mathrm{g} \cdot \mathrm{cm}^{-3}\right)$ & $\varphi 300$ & $\varphi 200$ & $\varphi 100$ & $\varphi 6$ & $\varphi 3$ & 24h compressive strength $(\mathrm{MPa})$ \\
\hline $10: 0$ & 1.5 & 275 & 214 & 157 & 24 & 19 & 8.2 \\
$9: 1$ & 1.5 & 261 & 198 & 145 & 22 & 18 & 8.9 \\
$8: 2$ & 1.5 & 263 & 186 & 153 & 19 & 15 & 9.2 \\
$7: 3$ & 1.5 & 247 & 169 & 134 & 19 & 14 & 9.8 \\
$6: 4$ & 1.5 & 244 & 174 & 136 & 17 & 14 & 10.5 \\
$5: 5$ & 1.5 & 246 & 171 & 124 & 17 & 13 & 11.6 \\
$4: 6$ & 1.5 & 239 & 178 & 132 & 16 & 13 & 12.3 \\
$3: 7$ & 1.5 & 236 & 172 & 119 & 17 & 14 & 13.7 \\
$2: 8$ & 1.5 & 221 & 168 & 113 & 16 & 12 & 14.3 \\
$1: 9$ & 1.5 & 228 & 161 & 107 & 14 & 10 & 14.1 \\
$0: 10$ & 1.5 & 219 & 151 & 103 & 13 & 10 & 14.6 \\
\hline
\end{tabular}

TABLE 3: Components of the low-density mixture and their proportions.

\begin{tabular}{lccccc}
\hline Component & Microbeads & Volcanic ash microbeads & Microsilicon & Fly ash & Slag \\
\hline Proportion (\%) & 10.5 & 4.5 & 35 & 30 & 20 \\
\hline
\end{tabular}

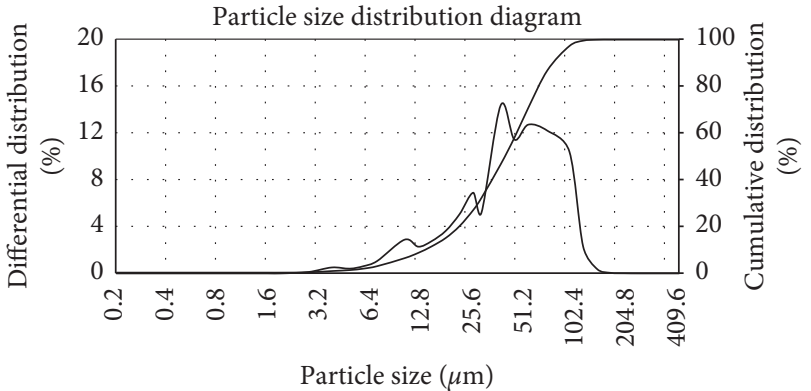

(a)

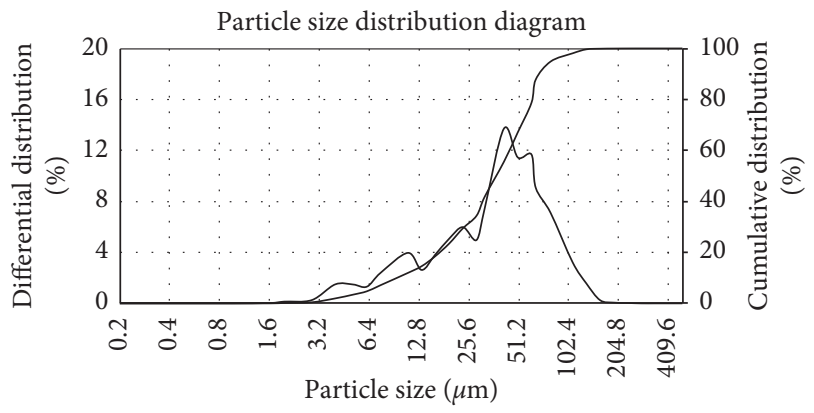

(c)

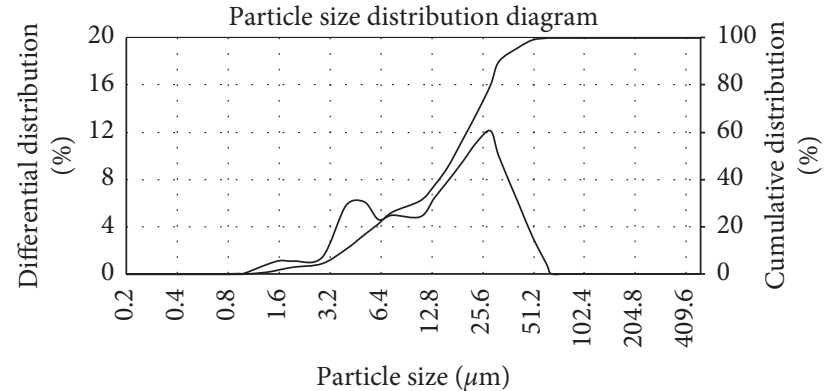

(b)

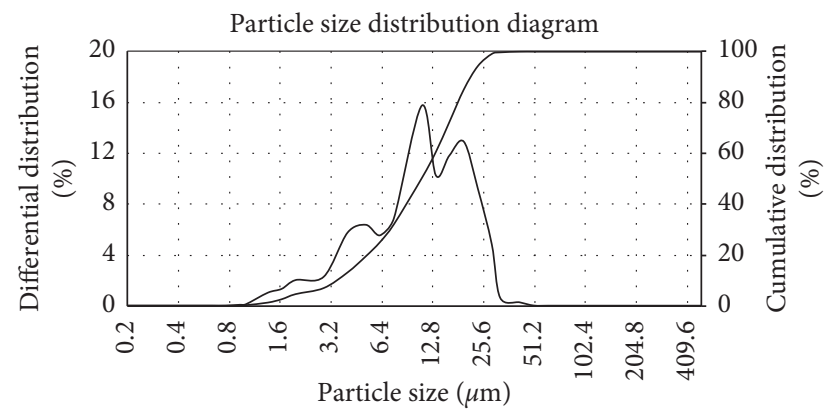

(d)

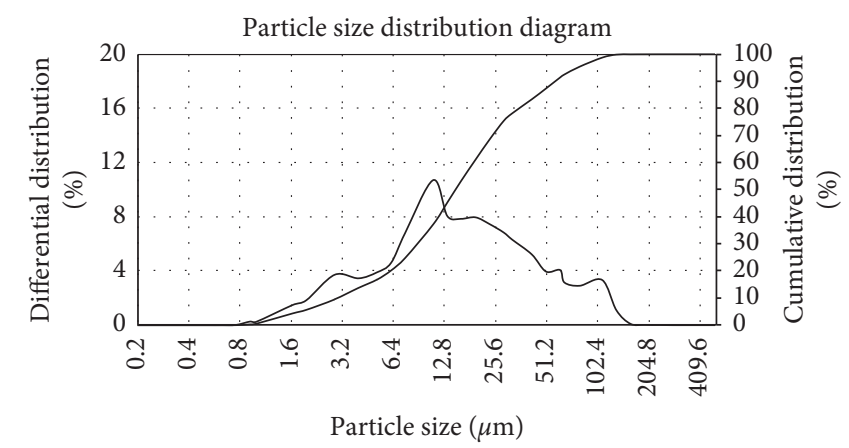

(e)

Figure 1: (a) Particle size distribution of microbeads, (b) Particle size distribution of slag, (c) Particle size distribution of fly ash, (d) Particle size distribution of microsilicon and (e) Particle size distribution of the low-density mixture. 

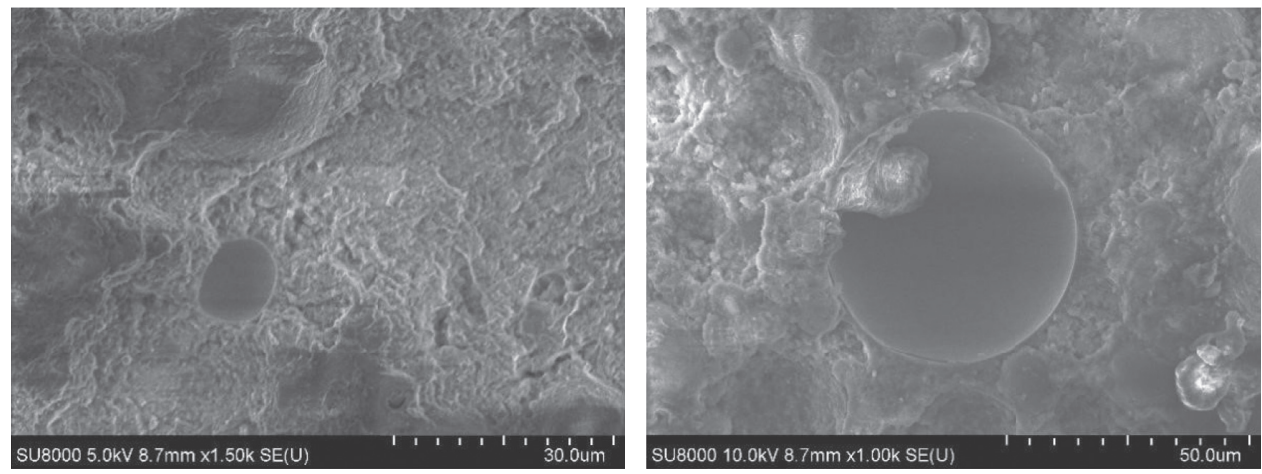

FIGURE 2: Micromorphology of low-density cement stone.

performance of the cement slurry. Particles with different particle sizes exert a ball bearing effect on the mix, which results in lower slurry yield point $(y)$ between the particles and improved mixing performance and pumping performance; although the water content is lower, the solid content is higher. The advantage of the larger PVF value is that the water content is correspondingly reduced and the proportion of cement is relatively increased to improve the compressive strength of the cement stone. The PSD slurry, due to its particle network and corresponding reduction in the water content, inhibits the sedimentation and separation of solid and liquid phases during well cementing, and the fine particles in the mix also play a good role in suspension, ensuring that the slurry maintains a good stability. The porosity of these systems is usually between $35 \%$ and $45 \%$ [20], and a reduction in slurry porosity ensures the early development of compressive strength. An improvement in fluidity results in a more reasonable particle distribution in the cement slurry system, a smaller contact angle of the hydration film between the particles, and a smaller frictional resistance. Therefore, the experiment is designed to calculate the PVF of the dry mix at a higher value to ensure the early strength of the cement slurry at low temperatures and the cementing strength of the unconsolidated sandstone.

The linear stacking theory model is shown in formula (1). The system is assumed to contain $\mathrm{n}$ particle grades, a size of $d_{i}$ for the size set when $i$ exists alone at the accumulation rate of epsilon $\varepsilon_{i}$, the system accumulation rate of $r_{i}$ and the volume fraction of the particle size of eta $\eta_{i}$ in linear relationship. The size of each $d_{i}$ size set is established for continuous accumulation, and the $r_{\mathrm{i}}$ accumulation rate is calculated for the youngest system to the most dense accumulation rate of the system theory:

$$
\begin{aligned}
r_{i} & =\frac{\varepsilon_{i}}{1-\sum_{j=1}^{i-1}\left[1-\varepsilon_{i}+\omega(i \cdot j) \varepsilon_{i}\left(1-\left(1 / \varepsilon_{j}\right)\right)\right] \eta_{j}-\sum_{j=i+1}^{n}\left[1-l(i \cdot j)\left(\varepsilon_{i} / \varepsilon_{j}\right)\right] \eta_{j}}, \\
l(i \cdot j) & =\sqrt{1-\left(1-\frac{d_{i}}{d_{j}}\right)^{1.02}}, \\
\omega(i, j) & =\sqrt{1-\left(1-\frac{d_{j}}{d_{i}}\right)^{1.50}},
\end{aligned}
$$

where $l(i, j)$ is the loosening effect of reducing the accumulation rate of large particles due to the presence of small particles and $\omega(i, j)$ is the wall effect of reducing the accumulation rate of small particles due to the presence of large particles.

Therefore, in this study, multiple particle size mitigating agents were used for compounding to form the spatial distribution of the microbeer-cement-slag-microsilicon level, the PVF value reached 0.89 , and the accumulation rate was high, which effectively improved the performance of the cement slurry.
3.2. Performance of the Cement Slurry System. The author took the Three Gorges cement and low-density mixture as the main component, selected the early strength agent, dispersant, fluid loss agent, antifoaming agent, and other admixtures, designed the cement slurry system formula with a density of $1.40 \mathrm{~g} / \mathrm{cm}^{3}$ to $1.70 \mathrm{~g} / \mathrm{cm}^{3}$, and measured the comprehensive performance of the low-density cement slurry according to API RP 10B-2. The conventional properties of the cement slurry mainly include the rheology, water loss, free liquid, thickening time, and compressive strength. Rheology determines the pumping ability and 
construction safety of cement slurry during the cementing operation [21]. The water loss of cement slurry is the free water that is filtered out through a certain pore area at a specified temperature and pressure difference, which is closely related to the cementing quality [22]. The free liquid is an important criterion for evaluating the stability of cement slurry systems [23]. The thickening time of the cement slurry is a very important parameter to measure and ensure the safety of pumping and construction [24]. Compressive strength is the key factor that ensures the effective sealing of the annulus [25].

3.2.1. Density Measurement. Since the microbeads and volcanic ash microbeads are hollow materials, they are broken at a certain pressure, resulting in an increase in the density of the cement slurry. The compressive strength of the volcanic ash microbeads is approximately 3000 psi. If this value is exceeded, some of the spheres may break, resulting in an increase in the density of the cement slurry system and changes in other performance measures of the cement slurry. Therefore, the choice of volcanic ash microbeads should consider the effect of downhole pressure. When the downhole pressure is too large, it is not appropriate to use volcanic ash microbeads, and artificial microbeads with better performance should be selected.

Therefore, this study measured the densities at ambient pressure and after the application of different pressures, as shown in Table 4 . The density of the cement slurry system increased when the applied pressure exceeded $20 \mathrm{MPa}$, which should be considered in the well cementing operation.

3.2.2. Rheological Properties. As a non-Newtonian thixotropic liquid, the rheological parameter "yield value" of the cement slurry is related to the force generated by breaking the bonds between particles. The most effective method for destroying the structure is to reduce the binding force of the structure and particles through the adsorption of chemical additives that dilute the dispersive viscosity. Therefore, the addition of a dispersant in a certain period of time increases the water to capillary permeability, reduces the "yield value," and improves the rheology of cement slurry, which is conducive to the field pumping operation.

In the present study, CF42L was selected as the dispersant for the cement slurry system, and the rheological properties of the cement slurry were tested under different quantities of added dispersant, as shown in Table 5. As the quantity of added dispersant increases, the rheological properties of the cement slurry are continuously improved. When the quantity reaches $4 \%$, the rheological properties of the cement slurry are substantially improved. When the quantity is greater than $4 \%$, the improvement in the rheological properties of the cement slurry will slow, even if the amount of dispersant continued to increase. When the amount of dispersant exceeds $8 \%$, a small amount of free water appears. The amount of CF42L must be controlled to a reasonable quantity during use to effectively reduce the cost.
TABLE 4: Density of the cement slurry system at different pressures. Density at ambient pressure $1.50 \mathrm{~g} / \mathrm{cm}^{3}$ Density after the application of $10 \mathrm{MPa}$ of pressure $1.50 \mathrm{~g} / \mathrm{cm}^{3}$ Density after the application of $20 \mathrm{MPa}$ of pressure $1.51 \mathrm{~g} / \mathrm{cm}^{3}$ Density after the application of $30 \mathrm{MPa}$ of pressure $1.55 \mathrm{~g} / \mathrm{cm}^{3}$

TABLE 5: Rheological properties of the cement slurry with different dispersant contents.

\begin{tabular}{lccccccc}
\hline $\begin{array}{l}\text { Dispersant } \\
\text { addition (\%) }\end{array}$ & $\Phi_{3}$ & $\Phi_{6}$ & $\Phi_{100}$ & $\Phi_{200}$ & $\Phi_{300}$ & $\Phi_{600}$ & $\begin{array}{c}\text { Free water } \\
(\%)\end{array}$ \\
\hline 0 & 17 & 21 & 103 & 149 & 188 & - & 0 \\
2 & 16 & 19 & 91 & 131 & 164 & 272 & 0 \\
4 & 12 & 15 & 77 & 116 & 149 & 225 & 0 \\
6 & 8 & 12 & 61 & 102 & 136 & 220 & 0 \\
8 & 6 & 10 & 53 & 95 & 126 & 197 & 0.2 \\
\hline
\end{tabular}

TABLE 6: Thickening time after the addition of different amounts of retarder.

\begin{tabular}{lc}
\hline RE-L $(\%)$ & Thickening time $\left(\mathrm{min} / 50^{\circ} \mathrm{C} \times 25 \mathrm{MPa}\right)$ \\
\hline 0 & 151 \\
0.5 & 172 \\
1.0 & 206 \\
1.5 & 223 \\
2 & 271 \\
2.5 & 300 \\
\hline
\end{tabular}

3.2.3. Thickening Time. In cementing design, the setting treatment must be slowed to achieve the pumping time required for cementing. The setting retarder ACTS increases the thickening time of cement slurry through surface adsorption and generation of surface precipitation.

In the present study, RE-L was selected as the retarder of the cement slurry system, and the thickening time of the cement slurry was tested after the addition of different amounts of the retarder, as shown in Table 6. According to Table 6 , the thickening time is obviously prolonged as the amount of added retarder increases, and the thickening time is adjustable within a certain range. As shown in Figure 3, the cement slurry system has a good thickening curve, approximately right-angle thickening, and thus, the appropriate amount of added retarder may be chosen according to the time in the well cementing operation.

\subsubsection{Free Water and Slurry Sedimentation Tests and Water} Loss. During the course of the cementing operation, due to the low density of the cement slurry and the high pressure difference in the liquid column produced during the pumping process, the cement slurry will exhibit "percolation" or leakage when it passes through the highly permeable formation, resulting in poor liquidity. In serious cases, the construction may fail. Therefore, by adding a filtration reducer to adjust the particle distribution of the cement slurry system, the filter cake gap is blocked to form dense filter cake. The water-soluble polymer is adsorbed on the surface of cement particles to form an adsorption hydration layer, and the cement particles are bridged to form a network 


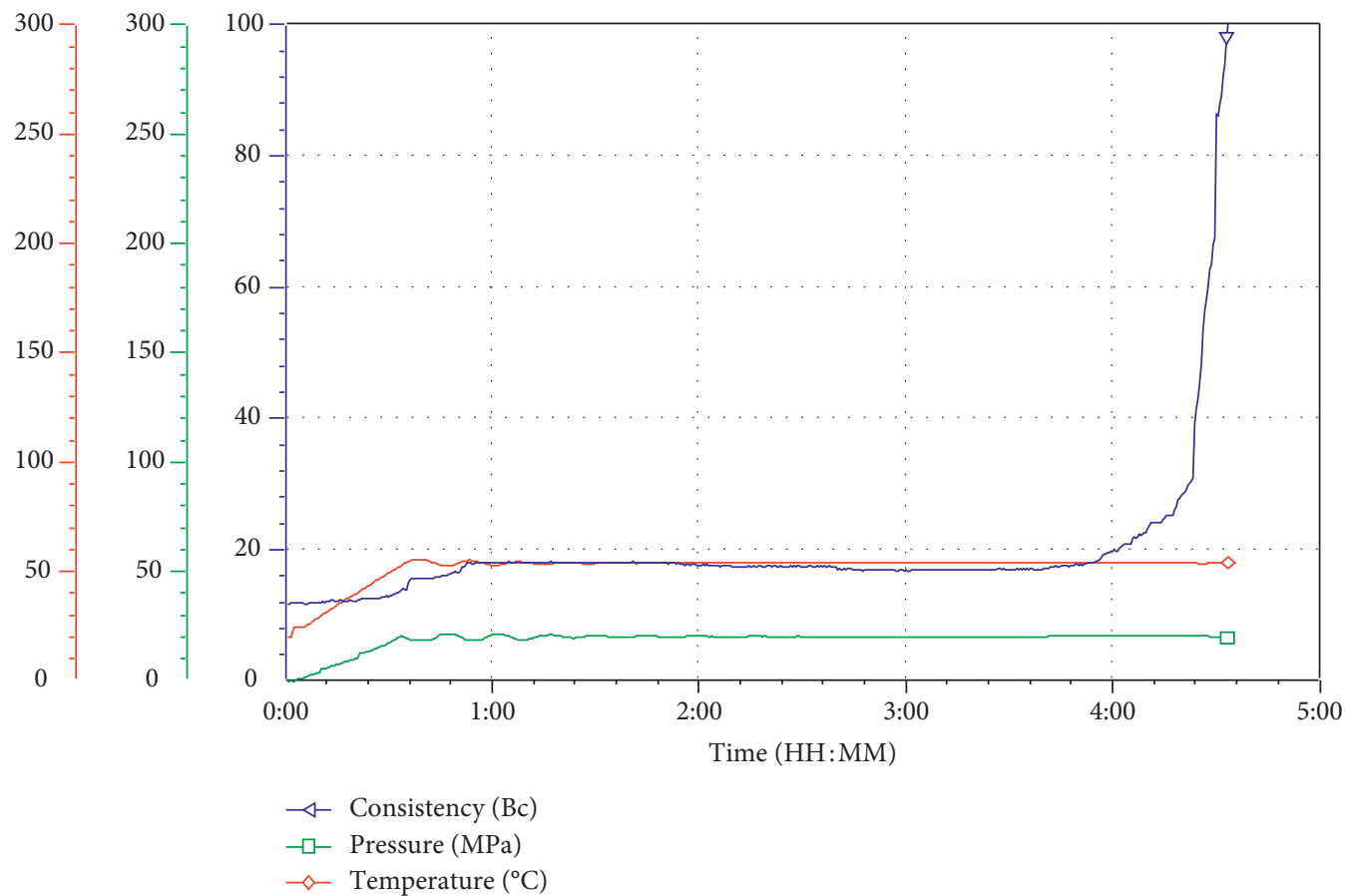

FIgURE 3: Thickening time $(271 \mathrm{~min})$ of the cement slurry containing $2 \%$ retarder.

structure, which binds more free water and blocks the internal pores of cement.

In this study, CG81L was selected as the filtration reducer for the cement slurry system. Table 7 records the data from the cement slurry sedimentation stability and free water experiments; although a density difference exists between upper and lower parts of the cement stone, the density difference is standardly acceptable within $0.02 \mathrm{~g} / \mathrm{cm}^{3}$, without substantial effects on the cement stone. The cement slurry system has a free water content of $0 \%$ and a water loss of $41 \mathrm{~mL}$, which indicates a good performance.

3.2.5. Compressive Strength. The compressive strength is the maximum force that the specimen can bear when it is destroyed. The cement stone requires good compressive strength to support the protective casing.

The low-density cement slurry system displays a slow increase in strength in the early stage, and thus ACL (a matching early strength agent) is preferred. ACL is an inorganic early strength agent with a relatively low price, and in the presence of ACL, the C-S-H gel can be transformed into a flocculent loose structure. The C-S-H gel, with a relatively high $\mathrm{C} / \mathrm{S}$ ratio and a wrinkled sheet structure, significantly increases the hydration rate and the permeability. Based on the results shown in Table 8, ACL exerts the most obvious effect on improving the early compressive strength of cement stone, without any adverse effects on the rheological properties.

The $24 \mathrm{~h}$ and $48 \mathrm{~h}$ compressive strengths and thickening time of cement stone at $50^{\circ} \mathrm{C}$ were measured by adjusting the amount of added ACL, and the results are shown in Table 9. According to Table 9, as the amount of added ACL increases, the strength of the cement stone gradually increases: the $24 \mathrm{~h}$
TABLE 7: Free water and slurry sedimentation experiments using the cement slurry.

\begin{tabular}{lc}
\hline Top & $1.50 \mathrm{~g} / \mathrm{cm}^{3}$ \\
Middle & $1.51 \mathrm{~g} / \mathrm{cm}^{3}$ \\
Bottom & $1.52 \mathrm{~g} / \mathrm{cm}^{3}$ \\
Difference & $0.02 \mathrm{~g} / \mathrm{cm}^{3}$ \\
Free water & $0 \%$ \\
Water loss & $41 \mathrm{~mL}$ \\
\hline
\end{tabular}

compressive strength is greater than $12 \mathrm{MPa}$, and the $48 \mathrm{~h}$ compressive strength is greater than $14 \mathrm{MPa}$, meeting the construction requirements. When the amount of ACL exceeds $2 \%$, the magnitude of the increase in the early compressive strength decreases. The addition of ACL shortens the thickening time of the cement slurry, and the difference in thickening time is small in the presence of different amounts of added ACL, but the thickening time is significantly shorter than the cement slurry without the early strength agent.

The early strength agent was added to the cement slurry at a concentration of $2 \%$ to measure the compressive strength within one week at $50^{\circ} \mathrm{C}$ and $15 \mathrm{MPa}$, and the results are shown in Figure 4. The strength of the cement slurry system is greater than $13 \mathrm{MPa}$ at 24 hours, with a rapid increase in early strength and a subsequently stable increase in strength, which meet the strength requirements of well cementing in shallow unconsolidated sandstone.

3.2.6. Comprehensive Performance of the Cement Slurry System. Finally, the formulation of the cement slurry system was determined, as shown in Table 10, and the test results of the cement slurry system are summarized in Table 11. The 
TABLE 8: Effect of different early strength agents.

\begin{tabular}{lcccccccc}
\hline Early strength agent & Density $\left(\mathrm{g} / \mathrm{cm}^{3}\right)$ & $\Phi 3$ & $\Phi 6$ & $\Phi 100$ & $\Phi 200$ & $\Phi 300$ & $\Phi 600$ & $24 \mathrm{~h}$ compressive strength $(\mathrm{MPa})$ \\
\hline Blank & 1.5 & 10 & 16 & 83 & 124 & 156 & 231 & 11.02 \\
SD-1 & 1.5 & 9 & 15 & 77 & 116 & 150 & 221 & 11.62 \\
ACL & 1.5 & 5 & 8 & 70 & 110 & 144 & 220 & 12.82 \\
APS & 1.5 & 10 & 15 & 76 & 115 & 147 & 224 & 12.15 \\
CS-3 & 1.5 & 31 & 43 & 97 & 128 & 160 & 248 & 10.72 \\
XN-1 & 1.5 & 17 & 22 & 83 & 115 & 139 & 217 & 10.1 \\
CG-4 & 1.5 & 21 & 30 & 91 & 127 & 151 & 228 & 10.52 \\
\hline
\end{tabular}

TABLE 9: Effect of the amount of added ACL on the performance of the low-density cement slurry.

\begin{tabular}{lccc}
\hline Amount of added ACL $(\%)$ & 24h compressive strength $(\mathrm{MPa})$ & 48 h compressive strength $(\mathrm{MPa})$ & Thickening time $(\mathrm{min})$ \\
\hline 0 & 11.02 & 13.14 & 212 \\
1 & 12.23 & 15.13 & 174 \\
2 & 13.72 & 15.82 & 167 \\
3 & 14.06 & 16.04 & 156 \\
4 & 14.22 & 16.46 & 151 \\
5 & 14.53 & 16.79 & 142 \\
\hline
\end{tabular}

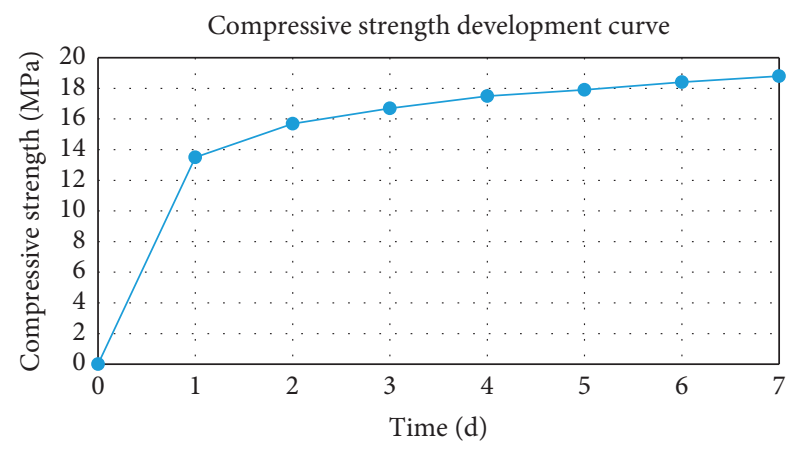

Figure 4: Compressive strength development curve.

TABLE 10: Formulation of the low-density cement slurry.

\begin{tabular}{lcc}
\hline Component & Unit & Proportion \\
\hline Density & $\mathrm{g} / \mathrm{cm}^{3}$ & 1.50 \\
Class-G cement & \%bwoc & 100 \\
Water & \%bwoc & 102 \\
Low-density mixture & \%bwoc & 70 \\
Early strength agent & \%bwoc & 2 \\
Enhancer & \%bwoc & 1 \\
Filtration reducer & \%bwoc & 6 \\
Dispersant & \%bwoc & 4 \\
Retarder & \%bwoc & 2 \\
Defoamer & \%bwoc & 1 \\
\hline
\end{tabular}

TABLE 11: Performance of the cement slurry system.

\begin{tabular}{lc}
\hline Test content & Result \\
\hline Density $\left(\mathrm{g} / \mathrm{cm}^{3}\right)$ & 1.50 \\
Rheological property & \\
$(\Phi 3 / \Phi 6 / \Phi 100 / \Phi 200 / \Phi 300 / \Phi 600)$ & 273 \\
Thickening time $(\mathrm{min})$ & 41 \\
Water loss $(\mathrm{mL})$ & 0 \\
Free solution $(\%)$ & 0.02 \\
Sedimentation stability $\left(\mathrm{g} / \mathrm{cm}^{3}\right)$ & 14.2 \\
$24 \mathrm{~h}$ compressive strength $(\mathrm{MPa})$ & \\
\hline
\end{tabular}

cement slurry system meets the well cementing requirements for the shallow unconsolidated sandstone stratum and achieves good application results in the well cementing operation.

3.2.7. Effects of Different Temperatures. In the process of well cementing construction, a certain difference in the bottom hole temperature exists due to the difference in stratum depth. The ambient temperature exerts a substantial effect on performance of the cement slurry; therefore, the performance of the cement slurry was measured at $30^{\circ} \mathrm{C}, 40^{\circ} \mathrm{C}$, and $50^{\circ} \mathrm{C}$ in the present study, as shown in Table 12 . The temperature exerts significant effects on the rheological properties, thickening time, and compressive strength of the cement slurry, but less of an effect on the stability and water loss of the cement slurry. As the temperature increases, the rheological properties of the cement slurry continuously improve, because the increase in the temperature is conducive to the flow of the low-density cement slurry, which can maintain a good stability. At a lower temperature, the hydration of the cement is slow, resulting in an increase in the thickening time of the cement slurry and a decrease in compressive strength of the cement slurry after curing for 24 hours. The water loss of the low-density cement slurry under different temperature conditions does not change substantially. Therefore, the lower temperature may exert an adverse effect on performance of the cement slurry, and at this moment, the quantity of additives must be changed to meet the requirements of well cementing construction.

\subsubsection{Effects of Different Pressures on the Performance of the} Cement Slurry. The author evaluated the performance of the cement slurry under different pressure conditions at $50^{\circ} \mathrm{C}$ indoors to study the effects of changes in pressure on the performance of the cement slurry, and the results are shown in Table 13. As the test pressure varies, the thickening time and postcuring compressive strength performance of the 
TABle 12: Performance of the cement slurry system at different temperatures.

\begin{tabular}{lcccc}
\hline Test temperature $\left({ }^{\circ} \mathrm{C}\right)$ & $\begin{array}{c}\text { Rheological properties } \\
(\Phi 3 / \Phi 6 / \Phi 100 / \Phi 200 / \Phi 300 / \Phi 600)\end{array}$ & Thickening time $(\mathrm{min})$ & Water loss $(\mathrm{mL})$ & $24 \mathrm{~h}$ compressive strength $(\mathrm{MPa})$ \\
\hline 30 & $6 / 9 / 84 / 144 / 199 /-$ & 323 & 38 & 12.2 \\
40 & $6 / 9 / 67 / 115 / 176 / 285$ & 288 & 39 & 13.5 \\
50 & $5 / 8 / 61 / 103 / 156 / 245$ & 273 & 41 & 14.2 \\
\hline
\end{tabular}

TABle 13: Pressure and cement slurry performance.

\begin{tabular}{lcc}
\hline $\begin{array}{l}\text { Test pressure } \\
(\mathrm{MPa})\end{array}$ & $\begin{array}{c}\text { Thickening time } \\
(\mathrm{min})\end{array}$ & $\begin{array}{c}\text { Compressive strength } \\
(\mathrm{MPa})\end{array}$ \\
\hline 0 & 312 & 14.2 \\
10 & 301 & 13.8 \\
20 & 283 & 14.7 \\
30 & 268 & 15.5 \\
\hline
\end{tabular}

cement slurry show a regular variation. As the pressure increases, the thickening time of the cement slurry gradually decreases, and the compressive strength of the cement slurry increases. Thus, the pressure exerts a substantial effect on the cement slurry for the following reasons as analyzed in the present study: (1) some of the lightening admixtures are broken, altering the performance of the cement slurry; and (2) the pressure decreases the number of voids in the solid in the cement slurry, affecting the performance of the cement slurry. Since the pressure exerts a regular effect on the cement slurry, the pressure of the bottom hole stratum in the field application should be measured. The cement slurry change rule will only be mastered by accurately obtaining the real pressure data from the cement slurry sealing section in the experiment, thus providing better and more direct guidance for field operations.

\section{Conclusions}

(1) PVF is one of the most critical factors in the design of low-density cement slurry system, and the effect of the PVF value on the cement slurry system should be thoroughly considered. A low-density mixture with a high PVF value and excellent performance was developed by compounding multiple low-density materials based on the principle of the particle size distribution. The formula is $10.5 \%$ microbeads $+4.5 \%$ floating drifting beads $+35 \%$ microsilicon $+30 \%$ fly ash $+20 \%$ slag, with a PVF value up to 0.89 , and a high accumulation rate, which effectively improve the performance of the cement slurry.

(2) When microbeads and other materials are used as lightening admixtures, the effect of the downhole pressure on the cement slurry system should be thoroughly considered, as a higher downhole pressure will cause the microbeads to break, resulting in an increase in the density and a change in the performance of the cement slurry system.

(3) By analyzing the effects of the dispersant, retarder, and early strength agent on the performance of the cement slurry, the proper additive was selected to adjust the performance of the low-density cement slurry. The rheological property, thickening time, and early compressive strength of the cement slurry meet the requirements of the cementing operation.

(4) The density of the developed low-cost and lowdensity cement slurry system can be adjusted according to the needs of the operation. The slurry system is stable at different temperatures and pressures, with less water loss, a high compressive strength, and thickening time, meeting the cementing requirements.

\section{Data Availability}

The data used to support the findings of this study are included within the article.

\section{Conflicts of Interest}

Yue Jiaping is now a drilling engineer of CNOOC Research Institute (email: yuejp@cnooc.com.cn). The authors declare that they have no conflicts of interest.

\section{Authors' Contributions}

Yue Jiaping mainly engaged in the design and research of drilling engineering..

\section{Acknowledgments}

This study was funded by the Fourth Batch of Open Fund Projects of State Key Laboratory of Offshore Oil Exploitation.

\section{References}

[1] H. Li, X. Xiang, H. Zhang, J. Fu, and Z. Hu, "Study and application of anti-channeling cement slurry used in shallow gas zones in Bohai," Drilling Fluid \& Completion Fluid, vol. 32, no. 5, pp. 58-60, 2015.

[2] Z. Li, L. Qi, R. Liu, T. Gu, and J. Sun, "Experimental study on the integrity of low-density cement sheath with hollow microsphere," Petroleum Drilling Techniques, vol. 45, no. 3, pp. 42-47, 2017.

[3] A. Velayati, M. Roostaei, R. Rasoolimanesh, M. Soleymani, and V. Fattahpour, "Colloidal gas aphron (CGA) based foam cement system," Petroleum Exploration and Development, vol. 46, no. 6, pp. 1281-1287, 2019.

[4] K. Yang, Z. Xiang, M. Huang, F. Sun, and B. Hou, "Study and application of a low cost ultra-low density cement slurry," Drilling Fluid \& Completion Fluid, vol. 35, no. 4, pp. 92-96, 2018. 
[5] P. Li, F. Sun, Y. Xia, and J. Zeng, "Experimental study on a low-cost low density cement slurry," Drilling \& Production Technology, vol. 41, no. 2, pp. 91-94, 2018.

[6] Y. Li, "Shallow gas well cementing and channeling prevention technology," Advances in Petroleum Exploration and Development, vol. 12, no. 1, pp. 47-55, 2016.

[7] C. Wang, R. Wang, H. Yang, and F. Wang, "Research on low density cementing Technology of coalbed methane well," Advances in Petroleum Exploration and Development, vol. 10, no. 2, pp. 50-57, 2015.

[8] Z. Y. Li, C. Zhou, J. Y. Li, Q. B. Wu, and X. Y. Guo, "Laboratory study on low temperature rapid strength cement slurry," Advanced Materials Research, vol. 287-290, pp. 3127-3130, 2011.

[9] J. Gu, B. Yoon, H.-S. Lee, S.-H. Lee, and J.-S. Kim, "Highly concentrated aqueous suspension containing fine $\mathrm{SiC}$ particles," Ceramics International, vol. 45, no. 17, pp. 21819-21826, 2019.

[10] S. Sun, W. Zhang, and J. Liu, "A novel strategy to obtain superfine modified $\mathrm{SiC}$ powder with binary modifier-disperse black/sodium alginate and its mechanism study," Materials Research Express, vol. 6, no. 11, Article ID 115108, 2019.

[11] Y. U. Dongnian, "The research and application of low density cement slurry system at low temperature in Daqing oilfield," Advances in Petroleum Exploration and Development, vol. 14, no. 1, 2017.

[12] B. Wang, B. Chen, W. Yang, and B. Li, "Application status and development direction of cement slurry system in deepwatersurface," Oil Drilling \& Production Technology, vol. 37, no. 1, pp. 107-110, 2015.

[13] P. Sarmah, P. Yadav, and G. Agrawal, "High-strength lightweight cement optimized for weak formations-use of local raw material improves performance and operational latitude," in Proceedings of the 2015 SPE Oil \& Gas India Conference and Exhibition, November 2015.

[14] Z. Teng, X. Xing, and Y. Chang, "Research on hollow glass beads used in low-density cement slurry system," Drilling Fluid \& Completion Fluid, vol. 28, no. S1, pp. 23-25, 2011.

[15] L. Sha, L. Li, Y. Gao, Z. Chang, and P. Xing, "A substitute for hollow micro-spheres," Drilling Fluid \& Completion Fluid, vol. 41, no. 6, pp. 55-56, 2006.

[16] A. Hanif, Z. Lu, and Z. Li, "Utilization of fly ash cenosphere as lightweight filler in cement-based composites-a review," Construction and Building Materials, vol. 144, no. 2, pp. 373-384, 2017.

[17] A. A. Doan, A. C. Holley, L. Li, and M. G. Kellum, "A novel cement system to ensure slurry stability in horizontal well," in Proceedings of the 2017 SPE Oklahoma City Oil and Gas Symposium, March 2017.

[18] B. Huang, "Microscopic mechanisms and model design of close packing theory," Petroleum Drilling Techniques, vol. 41, no. 1, pp. 5-12, 2007.

[19] B. Huang, "Cementing material and process system optimized by tight packing theory," Drilling Fluid \& Completion Fluid, vol. 41, no. 6, pp. 4-12, 2001.

[20] J. Goenawan, R. Goncalves, M. Dooply et al., "Overcoming shallow hazards in deepwater malikai batch-set top-hole sections with engineered trimodal particle-size distribution cement," in Proceedings of the 2016 Offshore Technology Conference, Kuala Lumpur, Malaysia, March 2016.

[21] M. Michaux and C. Defosse, "Oil well cement slurries I. Microstructural approach of their rheology," Cement and Concrete Research, vol. 16, no. 1, pp. 23-30, 1986.
[22] D. Bülichen and J. Plank, "Role of colloidal polymer associates for the effectiveness of hydroxyethyl cellulose as a fluid loss control additive in oil well cement," Journal of Applied Polymer Science, vol. 126, no. S1, pp. E25-E34, 2012.

[23] R. P. Matson, M. J. Rogers, V. C. Go Boncan, and R. G. Gandy, "The effects of temperature, pressure, and angle of deviation on free water and cement slurry stability," in Proceedings of SPE Annual Technical Conference and Exhibition (SPE-22551MS), Dallas, TX, USA, October 1991.

[24] A. Saasen, E. Rafoss, and A. Behzadi, "Experimental investigation of rheology and thickening time of class $G$ oil well cement slurries containing glycerin," Cement and Concrete Research, vol. 21, no. 5, pp. 911-916, 1991.

[25] M. Rupasinghe, P. Mendis, T. Ngo, T. N. Nguyen, and M. Sofi, "Compressive strength prediction of nano-silica incorporated cement systems based on a multiscale approach," Materials \& Design, vol. 115, pp. 379-392, 2017. 